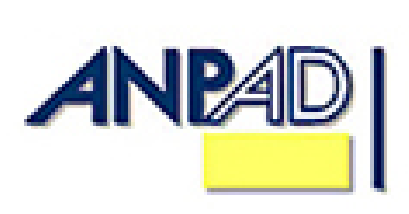

Disponível em

http://www.anpad.org.br/rac

RAC, Curitiba, v. 14, n. 6, art. 5,

pp. 1073-1093, Nov./Dez. 2010

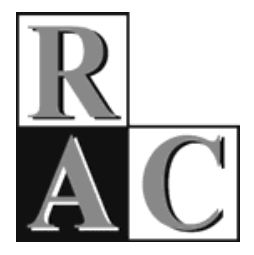

\title{
Arquiteturas Organizacionais para a Área de P\&D em Empresas do Setor Elétrico Brasileiro
}

\section{Organizational Architectures for R\&D in Brazilian Electrical Companies}

Jaelton Avelar Fernandino *

Mestre em Administração pela PUC-Minas. Gerente da Área de Gestão Tecnológica da CEMIG, Belo Horizonte/MG.

Janete Lara de Oliveira Doutora em Administração pelo CEPEAD/FACE/UFMG. Professora do CEPEAD/UFMG, Belo Horizonte/MG.

* Endereço: Jaelton Avelar Fernandino

Av. Barbacena, 1200, Belo Horizonte/MG, 35700-412. E-mail: jaelton@cemig.com.br

Copyright (C) 2010 RAC. Todos os direitos, inclusive de tradução, são reservados. É permitido citar parte de artigos sem autorização prévia desde que seja identificada a fonte. 


\title{
RESUMO
}

Este artigo busca identificar os modelos de arquiteturas organizacionais que estão sendo adotados por empresas do setor elétrico brasileiro para gerenciar o programa de Pesquisa e Desenvolvimento [P\&D] instituído a partir da Lei n. 9.991 (2000) e operacionalizado pela Agência Nacional de Energia Elétrica [ANEEL]. Adotaram-se as cinco dimensões propostas pelo Modelo Estrela de Galbratih (1995): estratégia, estrutura, processos, pessoas e sistemas de recompensa para analisar como as concessionárias de energia elétrica estão estruturando suas áreas de P\&D. Foram pesquisadas quatro concessionárias de energia elétrica, por meio de análise documental e entrevistas; os resultados indicam a existência, basicamente, de dois modelos de arquiteturas para estruturação da área de $\mathrm{P} \& \mathrm{D}$ dessas empresas. O primeiro apresenta-se mais estruturado, em termos do planejamento de $\mathrm{P} \& \mathrm{D}$, e é gerenciado por meio de estrutura organizacional informal e enxuta. Os investimentos para treinamento são modestos, bem como os incentivos de participação. O segundo identifica a existência de áreas formais para gerenciamento do programa, embora as estratégias para investimentos em P\&D não se encontrem bem definidas. Novos estudos que possibilitem avaliar a relevância do modelo de arquitetura organizacional adotado para o desempenho das carteiras de projetos são pertinentes e relevantes.

Palavras-chave: arquitetura organizacional; programa de pesquisa e desenvolvimento; gerenciamento de P\&D.

\begin{abstract}
This article aims to evaluate the organizational architecture models currently being adopted by the Brazilian electrical energy companies to properly manage the Program of Research and Development [R\&D], instituted by Law 9.991 (2000) and made operational by the Brazilian Electrical Energy Agency [ANEEL]. As a conceptual research model, the five dimensions proposed by Galbratih's Star Model (1995) were used: strategy, structure, processes, people and reward systems. The research was conducted with four concessionaries of electrical energy through interviews and documental analysis, and the results indicate the existence, basically, of two models of architecture for the structuring of the R\&D area. The first model is found in companies that use a more structured planning of R\&D, even though they manage it through an informal and small organizational structure. The investments made in training are relatively few, as are incentives for participation. In the second group, there is an indication of the existence of formal areas for the management of the program, even though the strategies for investing in R\&D have yet to be well defined. New studies that allow for the evaluation of effectiveness of organizational architectures concerning the performance of the projects portfolio are pertinent and necessary.
\end{abstract}

Key words: organizational architecture; research and development program; management of R\&D. 


\section{INTRODUÇÃO}

Até os anos 90, o setor elétrico era operado, na sua maioria, por empresas estatais em mercados protegidos por monopólios regionais e com tarifas nacionalmente uniformes. A partir dos anos 90, começou a ser desenvolvido o Programa Nacional de Desestatização, com o objetivo de desverticalizar e privatizar as empresas do setor, além de criar um Operador Nacional do Sistema [NOS] e um órgão regulador - a Agência Nacional de Energia Elétrica [ANEEL], cujo objetivo foi definido como o de criar regras e fiscalizar o funcionamento do setor instituído sob novas premissas.

Em julho de 2000, o Governo Federal promulgou a Lei n. 9.991, que instituiu como obrigação para as empresas do Setor Elétrico Brasileiro [SEB] a aplicação de, pelo menos, 1\% de sua Receita Operacional Líquida [ROL] em desenvolvimento de projetos de pesquisa e em desenvolvimento tecnológico. Maiores investimentos em $\mathrm{P} \& \mathrm{D}$ passaram a constituir uma exigência instituída pela agência reguladora das concessionárias do setor elétrico, formulada com diversos objetivos: fazer com que as concessionárias desenvolvessem uma visão mais voltada para o longo prazo, aumentar a produtividade e a competitividade das empresas do setor, possibilitar o desenvolvimento de tecnologias alternativas, bem como ampliar a interação com a sociedade, apoiar grupos de pesquisa e facilitar a articulação universidade-empresa.

A legislação instituída concedia às empresas do setor do SEB autonomia para captar, selecionar e gerenciar projetos de P\&D para contratar pesquisadores, centros de pesquisa e universidades, bem como para criar as estruturas internas necessárias para o encaminhamento do programa. Aliada à autonomia na gestão dos programas, contudo, as empresas tinham agora o desafio de criar uma nova filosofia de P\&D nas empresas do setor, desenvolvendo e implementando as estratégias necessárias para desenvolver produtos e serviços que atendam às demandas do setor elétrico.

Para Visacro (2005), ao atribuir às empresas concessionárias a responsabilidade pela definição dos projetos e por sua contratação, o Governo teve como objetivo imprimir credibilidade ao novo modelo, amparado em três parâmetros básicos: objetividade, competência e autorregulamentação. Os resultados até agora obtidos, entretanto, vêm sendo questionados por diversos segmentos da sociedade, que não conseguem perceber o benefício tangível ou efeito do investimento de mais de um bilhão de reais por parte das empresas do setor elétrico. (ANEEL, 2008).

a ANEEL tem procurado fiscalizar as empresas sem, no entanto, lograr seus principais objetivos: obter resultados e gerar inovação. Apesar de todas as iniciativas, muitas empresas do setor ainda não encaram os recursos de P\&D da ANEEL como oportunidade de negócio ou possibilidade de retornos financeiros ou humanos, percebendo o Programa como obrigação, não se preocupando em investir de forma eficiente (Maisonnave \& Rocha-Pinto, 2008, p. 1).

Os primeiros ciclos de P\&D nas empresas do SEB foram caracterizados pela implementação de processos empíricos de desenvolvimento e gestão de projetos, em sua maioria capitaneados pelas áreas técnicas das empresas. Gradativamente, contudo, pode-se perceber a incorporação mais sistemática das atividades de $\mathrm{P} \& \mathrm{D}$ atreladas aos programas de planejamento estratégico empresarial e aos programas de educação corporativa (Martini \& Maffei, 2005). No final de oito anos de utilização dessas novas políticas de geração de $\mathrm{P} \& \mathrm{D}$, que já consumiu mais de um bilhão de reais, é necessária uma reflexão sobre o aprendizado que essa experiência tem proporcionado.

Ao longo dos últimos anos, as concessionárias vêm investindo cerca de R\$200 milhões/ano em pesquisa e desenvolvimento (Pompermayer \& Melo, 2005), um expressivo volume de recursos a ser gerido, o que demanda modificações nas estratégias, nas estruturas e nos processos dessas empresas, além de mudanças comportamentais. Mais do que apenas atender às exigências do órgão regulador, espera-se que as concessionárias sejam também capazes de utilizar esse novo arcabouço para gerar conhecimentos e produtos estratégicos, viáveis, comercializáveis e relevantes para a empresa, para o setor e para a sociedade. Buscando contribuir para ampliar as perspectivas do debate, a questão central deste trabalho consiste em avaliar os desafios apresentados pelo novo marco regulatório do setor 
elétrico numa perspectiva organizacional, isto é, como as concessionárias do setor de energia estão (re)configurando suas arquiteturas organizacionais para desenvolver novas estratégias, novas atividades, novos processos e envolver novos atores nessa complexa dinâmica.

Questões relativas às interseções entre ambiente, estratégias, estruturas e processos organizacionais foram exaustivamente tratadas no contexto da teoria contingencial, mas continuam atuais e relevantes. Embora sejam conhecidas as interfaces prováveis dessas variáveis, são inúmeras as possibilidades apresentadas pelas organizações no sentido de criar possibilidades, inovar e combinar recursos que continuamente (re)criam suas arquiteturas organizacionais no sentido de oferecer a um ambiente dinâmico as respostas que, supostamente, influenciam a capacidade de sobrevivência e a efetividade das formas organizacionais (Donaldson, 1998; Lawrence \& Lorsch, 1973; Mintzberg, 1995; Nadler, Gerstein, \& Shaw, 1993).

Com base no Modelo Estrela de Galbratih (1995), que identifica cinco dimensões de arquitetura organizacional - Estratégia, Estrutura, Processo, Pessoas e Recompensa - esta pesquisa buscou identificar e analisar as arquiteturas organizacionais adotadas por algumas empresas do setor elétrico brasileiro para estruturar suas áreas de P\&D, criadas para atender à Lei n. 9.991/2000. Basicamente, buscou-se o alcance de quatro objetivos com a realização desta pesquisa: (1) identificar e analisar os tipos de configurações estruturais que estão sendo utilizados por empresas do setor elétrico brasileiro, para desenvolver a função P\&D; (2) avaliar as estratégias adotadas pelas áreas de P\&D das empresas do setor elétrico brasileiro e como elas causam impacto na escolha de determinada arquitetura organizacional; (3) identificar os macroprocessos mais importantes desenvolvidos internamente nas áreas de P\&D das empresas do setor elétrico brasileiro; (4) avaliar como as políticas de gestão de pessoas e recompensas influenciam a arquitetura organizacional das empresas do setor elétrico.

A pesquisa empírica foi realizada por meio de um estudo de casos múltiplos, de caráter exploratóriodescritivo, desenvolvido em quatro grandes concessionárias de energia elétrica do Brasil, a saber: a CPFL e a Eletropaulo, duas empresas privadas; a CEMIG, uma empresa de economia mista com participações do Estado de Minas e a Eletronorte, também uma empresa de economia mista, com participação de recursos do governo federal.

Analisar a arquitetura organizacional adotada pelas concessionárias de energia, após a promulgação da Lei n. 9.991, para a inserção da função P\&D constitui temática relevante, porque possibilita identificar particularidades de cada uma dessas arquiteturas e aponta aspectos que poderão ser refletidos por outras empresas em processos de reestruturação. Afinal, não se pode desconsiderar as possibilidades do isomorfismo institucional, que mostra a tendência de as organizações repetirem ações e adotarem modelos próximos daqueles adotados por empresas que apresentam características semelhantes e estão insertas num mesmo contexto que o seu (Dimaggio \& Powell, 2005).

Este trabalho está estruturado em mais cinco seções, além desta introdução. A próxima seção discorre sobre o setor elétrico nacional e sobre o programa de P\&D instituído pela ANEEL, via Lei n. 9.991 (2000). As terceira e quarta seções apresentam, respectivamente, uma revisão da literatura sobre arquitetura organizacional e o método de pesquisa empregado. $O$ resultado das pesquisas realizadas se encontra na quinta seção. Por fim, a sexta seção conclui o trabalho.

\section{O Setor Elétrico Brasileiro e o Programa de P\&D da ANEel}

Os anos 90 reuniram todos os fatores que poderiam contribuir para o agravamento de uma crise no SEB: o esgotamento da capacidade de geração de energia elétrica das hidrelétricas existentes, o aquecimento da economia provocado pelo Plano Real, a necessidade de novos investimentos e a escassez de recursos do governo para atender a essa necessidade que competia com diversas outras prioridades. 
Fazia-se necessário encontrar alternativas que viabilizassem tanto a reforma quanto a expansão do setor, para propiciar a entrada de investimentos de capitais privados, contexto no qual o governo deveria migrar de um papel de ofertante para outro de orientador e fiscalizador dos serviços de energia elétrica (Silva, Mora, \& Stal, 2008). Assim é que em 1996 foi implantado o Projeto de Reestruturação do Setor Elétrico Brasileiro (Projeto RE-SEB), em consequência da necessidade de viabilizar a desverticalização das empresas de energia elétrica, criando os segmentos de geração, transmissão e distribuição de energia. Os segmentos de geração e comercialização passaram até mesmo a atuar de forma competitiva entre si, mantendo sob a regulação do Estado os setores de distribuição e transmissão, considerados monopólios naturais.

Os pontos básicos da reforma consistiam em definir um modelo que reduzisse o risco de falta de energia, aumentasse a competição e a eficiência do sistema, incentivasse novos investimentos, sobretudo privados, assegurasse a melhoria da qualidade dos serviços com preços mais justos ao consumidor e possibilitasse a implementação e a diversificação da matriz geradora de energia. Pelo menos duas grandes questões emergiram com essa reforma: a necessidade de regular a concorrência por meio do estabelecimento de normas claras e eficazes e o imperativo de conciliar as funções de planejamento energético com um aparato institucional e legal que fornecesse segurança para a expansão do sistema. A definição de regras contratuais estáveis e de longo prazo tornava-se elemento fundamental para viabilizar investimentos privados, amortizáveis em prazos longos (Salgado \& Motta, 2005).

A primeira etapa das reformas começou a produzir efeitos antes que se estabelecesse o marco regulatório do setor e até mesmo antes da definição de políticas claras de planejamento energético. Esses equívocos e a necessidade de que se estabelecessem novas diretrizes para o setor levaram à paralisação do programa de privatizações no final dos anos 90. Em 2001, o setor elétrico sofreu grave crise de abastecimento, o que exigiu a elaboração de um plano de racionamento de energia elétrica, fato que gerou muitos questionamentos sobre os rumos que o setor elétrico estava trilhando e sobre seu futuro. Visando adequar o modelo em implantação, foi instituído, em 2002, o Comitê de Revitalização do Modelo do Setor Elétrico, cujo trabalho resultou em um conjunto de propostas de alterações para o setor. Nesse contexto, foi criada a ANEEL (Lei n. 9.427, 1996), o Operador Nacional do Sistema Elétrico [ONS] e o Mercado Atacadista de Energia Elétrica [MAE]. Em 2003 e 2004, foi lançado pelo Governo Federal um novo modelo para o setor elétrico brasileiro. Em termos institucionais, o novo modelo definia a criação de um órgão responsável pelo planejamento do setor elétrico de longo prazo - a Empresa de Pesquisa Energética [EPE], com a função de avaliar permanentemente a segurança do suprimento de energia elétrica, tarefa empreendida pelo Comitê de Monitoramento do Setor Elétrico [CMSE]. Foi criada também a Câmara de Comercialização de Energia Elétrica [CCEE], órgão encarregado de dar continuidade às atividades desenvolvidas no Mercado Atacadista de Energia Elétrica [MAE].

Concluído em agosto de 1998, o Projeto RE-SEB definiu o arcabouço conceitual e institucional do modelo a ser implantado no setor elétrico brasileiro, em que o Estado se desvinculava de seu papel de promover e executar as funções operacionais do sistema e assumia a função de regular a atuação, notadamente, de empresas privadas. Esse novo modelo trazia variáveis complexas à atuação do Estado, que deveria estabelecer normas para regular a competição das empresas e, ao mesmo tempo, realizar as atividades de planejamento energético de forma mais ampla e com horizonte de longo prazo (Salgado \& Motta, 2005).

Em relação à comercialização de energia, foram instituídos dois ambientes para celebração de contratos de compra e venda de energia: o Ambiente de Contratação Regulada [ACR], do qual participam Agentes de Geração e de Distribuição de energia elétrica, e o Ambiente de Contratação Livre [ACL], do qual participam agentes de geração, comercialização, importadores e exportadores de energia, bem como consumidores livres.

Grande parte das concessionárias de energia elétrica, especialmente as estatais, sempre se preocupou em manter modernos padrões tecnológicos. Com o surgimento de um ambiente concorrencial no setor elétrico, a redução nas margens de comercialização, as necessidades crescentes de investimentos e a 
preocupação com a qualidade da energia, melhorias nos modelos de gestão do setor passaram a ser vitais para a sobrevivência das empresas. É nesse contexto que os investimentos em tecnologia e inovação, bem como seu adequado gerenciamento, passam a representar papel fundamental para as concessionárias de energia. Deve-se ressaltar a relevância que as inovações, tanto tecnológicas quanto gerenciais, significam em termos das possibilidades de criar diferenciação na qualidade dos produtos e serviços e nos resultados empresariais.

O controle mais rígido dos gastos públicos e os processos de privatização das empresas estatais de serviço público propiciaram transformações no papel do Estado e do mercado em relação à definição de políticas de financiamentos de $\mathrm{P} \& \mathrm{D}$. Os recursos públicos passaram a ser direcionados para atender a tecnologias que gerassem resultados social e ambientalmente responsáveis; os recursos a serem destinados a P\&D pelas empresas do setor energético passaram a ser investidos em projetos que privilegiam os interesses estratégicos dessas empresas, mas que também possibilitam integrar pesquisas experimentais e inovadoras (Jannuzzi \& Gomes, 2002; Maisonnave \& Rocha-Pinto, 2008). Dois mecanismos foram criados para viabilizar essa estratégia: a criação do fundo setorial, CTENERG e a obrigatoriedade das empresas do setor de destinarem parte de seus lucros a projetos de P\&D. O fundo CT ENERG incentiva ações de P\&D endereçadas a questões de eficiência energética. Os investimentos das empresas vêm sendo objeto de regulamentação desde 1997 (Decreto 2.357, 1997; Resoluções ANEEL $n^{\circ}$ 242, 1998, $n^{\circ}$ 261, 1999, $n^{\circ}$ 271, 2001; Lei 9.991, 2000), quando as concessionárias de energia elétrica passaram a ter a exigência de aplicação compulsória de, no mínimo, $1 \%$ de sua receita operacional líquida em programas de pesquisa e desenvolvimento tecnológico.

O objetivo principal do governo, quando criou essa nova lei, foi assegurar o contínuo desenvolvimento tecnológico e de gestão do setor elétrico, num ambiente desregulamentado, composto, em sua maioria, por empresas privadas. Os projetos que podem ser desenvolvidos no âmbito do Programa Anual de P\&D do Setor Elétrico são aqueles cujas atividades, caracterizadas como P\&D, sejam implementadas pelas empresas de energia elétrica isoladamente ou com a participação de instituições públicas ou privadas de ensino e/ou de $\mathrm{P} \& \mathrm{D}$, empresas de consultoria ou fabricantes de materiais e equipamentos para o setor elétrico. A ANEEL (2001) considera atividade de $\mathrm{P} \& \mathrm{D}$ todas aquelas relacionadas à geração, transmissão, distribuição e comercialização de energia elétrica, empreendidas em base sistemática, com vistas a aumentar o estoque de conhecimentos, a aplicar esse estoque e a perscrutar novas aplicações. As atividades de P\&D são agrupadas em três categorias principais: pesquisa básica dirigida, pesquisa aplicada e desenvolvimento experimental (ANEEL, 2001).

A qualidade de um projeto de $P \& D$, por sua vez, é avaliada pela ANEEL em relação a dois fatores básicos: a natureza dos produtos desenvolvidos no que se refere à criatividade científica e à inovação tecnológica e sua potencialidade aplicativa. Adicionalmente, a ANEEL avalia e incentiva a capacitação e a disponibilidade da equipe envolvida nos projetos de P\&D, embora não se configurem como projeto de P\&D a simples formação e a capacitação de recursos humanos desvinculadas de projeto específico.

Sob o aspecto operacional, o sistema de investimentos em P\&D pelas empresas do setor elétrico se inicia com a submissão, por empresas, pesquisadores, centros de pesquisa de universidades e empresas, de projetos de pesquisa em conformidade com o manual disponibilizado pela ANEEL. De forma detalhada, esses projetos devem explicitar, justificar e orçar suas propostas, além de projetar outros aspectos, como contrapartidas institucionais, retornos esperados, expectativa de geração de conhecimento, entre outros. Os projetos selecionados pelas concessionárias e aprovados previamente pela ANEEL são então financiados e criteriosamente monitorados pela agência. Cada projeto de P\&D dura em média dois anos e, a cada despesa efetivamente realizada no projeto, a ANEEL deduz da conta de $\mathrm{P} \& \mathrm{D}$ da concessionária os valores dos investimentos realizados.

Uma vez que o estabelecimento do marco legal e regulatório precedeu a etapa de adequação a uma nova realidade, essas empresas tiveram de inserir as atividades de P\&D enquanto estratégicas em seus processos de planejamento, além de terem de criar novas estruturas, ou adaptar estruturas já existentes 
para abrigar atividades complexas, como captação, seleção, priorização, desenvolvimento e avaliação de projetos de cunho tecnológico. Este não parece estar sendo um trabalho simples para as concessionárias. Em pesquisa quantitativa e qualitativa realizada com gestores de P\&D de concessionárias de energia (geração, transmissão e distribuição), Maiosonnave e Rocha-Pinto (2008) avaliaram a percepção desses gestores acerca da efetividade das ações de inovação empreendidas por essas empresas. A pesquisa quantitativa pode mapear a percepção dos respondentes em relação a 19 dimensões relacionadas às estratégias de $\mathrm{P} \& \mathrm{D}$ das empresas, à percepção dos funcionários, ao papel dos agentes do setor e à avaliação dos resultados até então obtidos. A pesquisa qualitativa revelou muitas dificuldades por parte dos gestores desses projetos e pode-se perceber que as empresas do setor elétrico ainda estão em fase de estudos, implementação e avaliação da arquitetura organizacional mais adequada ao desenvolvimento de suas atividades de P\&D. Os autores apresentam, como resultado de sua pesquisa que:

a dinâmica das mudanças no ambiente de negócios, aliada à falta de comprometimento dos funcionários e apoio das gerências, provoca o isolamento da área de P\&D nas instituições do setor elétrico brasileiro ... [ou ainda] apesar dos processos de prospecção de temas e oportunidades, os gestores, muitas vezes, se vêem sem alternativas para gerar produtos de interesse da empresa (Maisonnave \& Rocha-Pinto, 2008, p. 11).

No contexto de um novo marco regulatório, as concessionárias do setor de energia viram-se rapidamente inseridas numa perspectiva ambiental e organizacional na qual têm de definir estratégias, ajustar estruturas e delinear processos internos de modo que respondam, de forma eficiente, à captação, seleção, gestão e desenvolvimento de projetos de P\&D. Embora relativamente recentes, as experiências de algumas concessionárias revelam como esses desafios vêm sendo enfrentados, o que será discutido a partir da quinta seção deste trabalho.

\section{FUNDAMENTAÇÃO TEÓRICA}

Nadler (1993) conceitua arquitetura organizacional como a forma de articulação, ou o modus operandi, dos vários sistemas, estruturas, processos e estratégias que constituem uma empresa. A arquitetura inclui, portanto, a estrutura formal, o projeto de práticas de trabalho, a natureza da organização informal, os estilos de operação e os processos de seleção, socialização e desenvolvimento de pessoal.

Numa analogia entre arquitetura organizacional e a dos espaços físicos, Gerstein (1993) conceitua a primeira como a arte de modelar o espaço organizacional para satisfazer as necessidades e as aspirações humanas. Nesse contexto, considera que novos projetos devem estar à frente de sua época e que, da mesma forma como os arquitetos convencionais trabalham o espaço tridimensional em que os indivíduos se movimentam, os arquitetos organizacionais operam no espaço comportamental em que as pessoas atuam. A criação de oportunidades para a ação, a imposição de limitações a essas ações e o desenho do projeto do espaço de informação constituem, entre outros, aspectos básicos da tarefa do arquiteto organizacional.

Para Nadler e Tushman (1993), a maioria dos administradores pensa as organizações em termos da estrutura formal representada pelo organograma clássico, que trata prioritariamente das relações estáveis e formais, entre as tarefas e as unidades de trabalho, excluindo o comportamento da liderança, o impacto do ambiente, as relações informais e a distribuição de poder. Esses autores identificam duas exigências, de certa forma conflitantes, que as atividades relativas à configuração da arquitetura organizacional devem considerar. Por um lado, deve-se pensar como a estrutura permitirá à organização implementar suas várias estratégias e realizar o trabalho exigido; por outro, deve considerar como a arquitetura se harmonizará com os indivíduos que trabalham na organização e para ela, ou como será o impacto das mudanças nas pessoas. 
Nadler e Tushman (1993) propuseram então o Modelo Congruente do Comportamento Organizacional, baseado nos conceitos e nas características dos sistemas abertos e fundamentado na ideia de que os diversos componentes do sistema se inter-relacionam e devem buscar o ajuste mútuo tal como se visualiza na Figura 1.

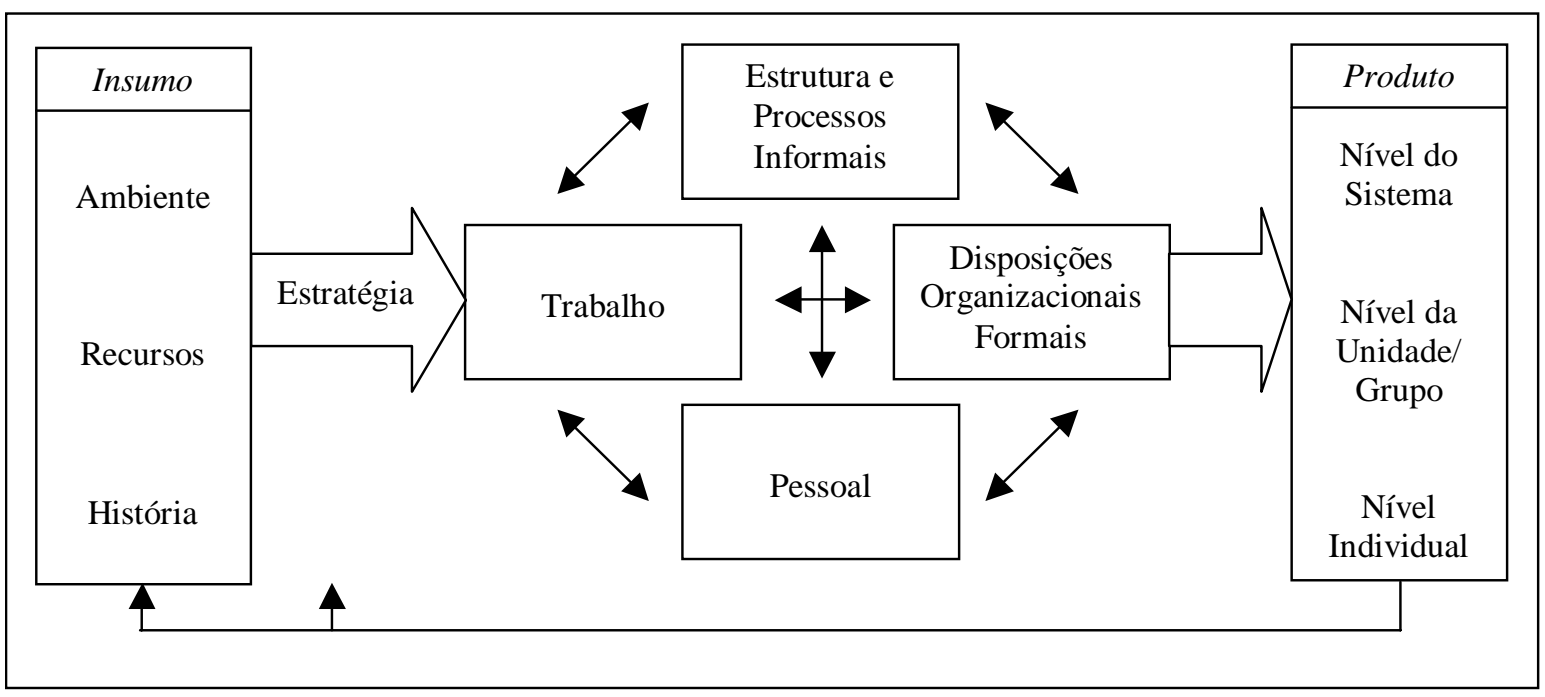

Figura 1. Modelo Congruente do Comportamento Organizacional.

Fonte: Nadler, D. A., \& Tushaman, M. L. (1993). Projetos de organizações com boa adequação: uma moldura para compreender as novas arquiteturas (p. 43). In D. A. Nadler, M. S. Gerstein, \& R. B. Shaw (Orgs.), Arquitetura organizacional: a chave para a mudança empresarial (pp. 29-49). Rio de Janeiro: Campus.

As estruturas organizacionais, bem como as formas de coordenação, formalização e descentralização variam com o que Mintzberg (1995) denominou fatores situacionais: ambiente, tamanho da organização, tecnologia ou processos produtivos utilizados. Outro fator que pode influenciar a estrutura organizacional é o porftolio das estratégias que a empresa adota para alcançar seus objetivos de crescimento e expansão. A otimização da estrutura irá variar de acordo com os fatores situacionais ou contingenciais da organização.

Estudos que avaliam o impacto de fatores ambientais na arquitetura das organizações datam da década de 50. Burns e Stalker (1961) associaram-na à questão da (in)certeza ambiental; Woodward (1977), à tecnologia e Lawrence e Lorsch (1973), à forma como a empresa lida com o problema da diferenciação e da integração. Na perspectiva da Teoria da Contingência Estrutural (Donaldson, 1998), fatores contingenciais, tais como a estratégia, a incerteza com relação às tarefas e a tecnologia, influenciam a arquitetura das organizações. Assim, para ser efetiva, a organização precisa adequar sua estrutura e seus fatores contingenciais ao ambiente.

Conforme Donaldson (1998, p. 105), “a teoria da contingência estabelece que não há uma estrutura organizacional única que seja altamente efetiva para todas as organizações. A otimização da estrutura variará de acordo com determinados fatores, tais como estratégia da organização ou seu tamanho”.

Galbratih (1995), embora confira maior importância à estratégia como direcionadora do desenho organizacional, identifica cinco categorias que influenciam a escolha da arquitetura de uma organização. Esse modelo, denominado por ele Modelo Estrela (Figura 2), é composto pelas dimensões: Estratégia, Estrutura, Processo, Pessoas e Recompensas. 


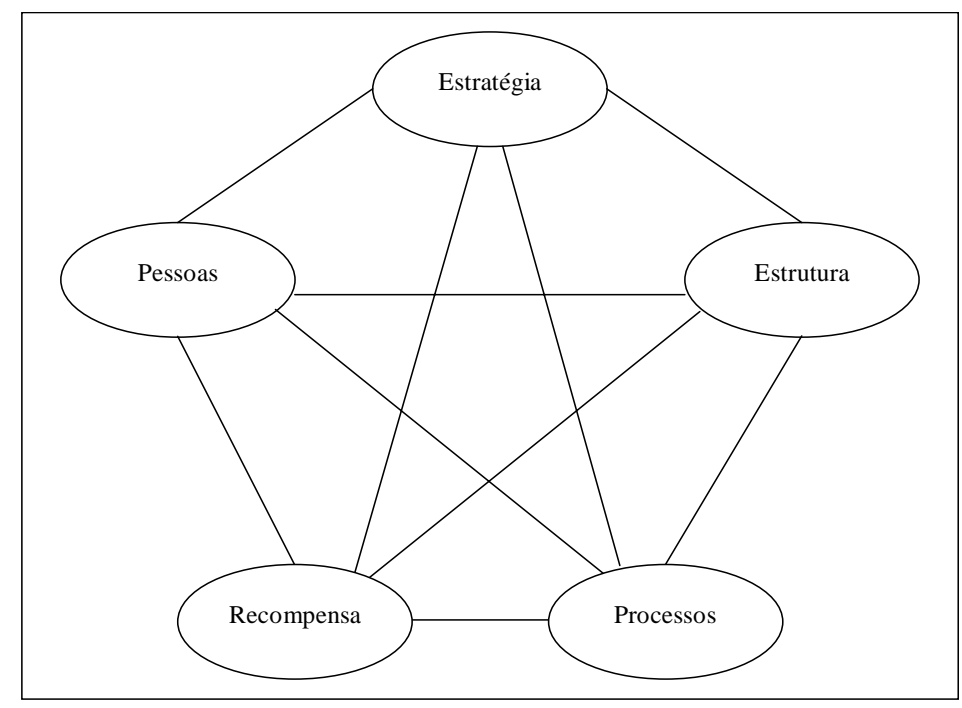

Figura 2. O Modelo Estrela de Galbratih

Fonte: Galbratih, J. R. (1995). Designing organizations - an executive briefing on strategy, structure and process. San Francisco, CA: Jossey Bass.

A dimensão Estratégia determina as metas e os objetivos da organização, assim como os valores e a missão a ser alcançada. Ela define os produtos ou serviços que serão oferecidos, o mercado ao qual servirá e os valores que a organização assumirá perante seus clientes. Ao definir a direção a ser seguida pela organização, ela estabelece os parâmetros que nortearão a escolha do desenho organizacional mais adequado para a implementação das estratégias.

A Estrutura define a forma como a organização distribui internamente o poder e a autoridade especialmente em relação a quatro aspectos básicos: (a) o tipo de especialização requerida para a realização do trabalho; (b) o formato de cada nível da estrutura; (c) os critérios a serem utilizados para a distribuição de poder, tanto na dimensão vertical quanto lateral; (d) os critérios de departamentalização que serão utilizados para definição das áreas que compõem cada um dos níveis da estrutura.

Os Processos descrevem os fluxos de informações que atravessam toda a empresa, podendo ocorrer tanto verticalmente, por meio da alocação de recursos escassos, talentos e recursos, como horizontalmente, via planejamento e fluxo de trabalho.

Na dimensão Pessoas, encontram-se as políticas de recursos humanos que norteiam a ação organizacional e que estão relacionadas às formas que serão utilizadas para identificar, recrutar, selecionar, contratar e promover os talentos que são requeridos pela estratégia e pela estrutura da organização, bem como as habilidades e conhecimentos que são necessários para implementar as escolhas estratégicas.

Por fim, no Sistema de Recompensas, encontram-se aqueles aspectos que influenciam a motivação e o comprometimento das pessoas com os objetivos da organização e que devem estar alinhados com a estrutura e os processos para influenciar a direção estratégica da organização.

O termo estrutura organizacional é usualmente referido como equivalente à arquitetura organizacional. Embora seja muito importante para o desenho da organização, porque reflete a alocação interna de poder e status, a estrutura não constitui sua face mais considerável. Também as dimensões processos, pessoas e recompensas têm-se tornado tão relevantes quanto ela, porque influenciam o desempenho e a cultura da organização. Nadler e Shaw (1993) consideram o projeto organizacional uma das ferramentas mais úteis ao fortalecimento da competitividade das organizações, na medida em que estruturas inovadoras tenderiam a aumentar sua eficiência e efetividade. 
Nesta pesquisa, pretende-se avaliar como algumas empresas do setor elétrico brasileiro estão formatando e buscando o equilíbrio de sua arquitetura organizacional, nas cinco dimensões mencionadas pelo Modelo Estrela de Galbratih (1995), para abrigar as atividades de pesquisa e desenvolvimento, introduzidas pela reforma do SEB.

\section{Metodologia da Pesquisa}

O problema de pesquisa aqui enfocado foi tratado por meio de uma pesquisa qualitativa, que procurou interpretar os fenômenos analisados e atribuir-lhes significados. Esse tipo de pesquisa considera que há relação dinâmica entre o mundo real e o sujeito, isto é, um vínculo indissociável entre o mundo objetivo e a subjetividade do sujeito, que não pode ser traduzido em números (Silva \& Menezes, 2001). Segundo Dencker (1998), indica-se essa metodologia de pesquisa, quando a análise das causas, condições e frequência de determinadas situações sociais, mediante sua observação controlada, auxiliam na compreensão do problema.

Do ponto de vista dos objetivos, esta pesquisa tem caráter exploratório, uma vez que visa proporcionar maior familiaridade com o problema, com vistas a torná-lo explícito (Silva \& Menezes, 2001). Lakatos e Marconi (2001) definem a pesquisa exploratória como investigações empíricas, cujo objetivo é a formulação de questões ou de um problema com tripla finalidade: desenvolver hipóteses, aumentar a familiaridade do pesquisador com um ambiente, fato ou fenômeno, para a realização de uma pesquisa futura mais precisa ou modificar e esclarecer conceitos. Gil (1991) considera que esse tipo de pesquisa tem como objetivo principal o aprimoramento de ideias ou a descoberta de intuições, sendo seu planejamento, portanto, bastante flexível, de modo que possibilite a consideração dos mais variados aspectos relativos ao fato estudado.

No caso específico desta pesquisa, optou-se pela realização de estudos de casos múltiplos em quatro grandes empresas do setor elétrico nacional. De acordo com Yin (2001, p. 68), "as provas resultantes de casos múltiplos são mais convincentes, e o estudo global é visto, por conseguinte, como sendo mais robusto". No entanto, esses tipos de estudos de casos são mais complexos de serem realizados, pois consistem em estudos aprofundados em mais de uma organização.

As unidades de análises escolhidas foram empresas concessionárias de energia elétrica brasileiras, de grande porte e reconhecidas no cenário nacional pela qualidade dos serviços que prestam. Foram realizadas pesquisas em duas empresas privadas: a CPFL e a Eletropaulo e em duas empresas de economia mista com participações acionárias do setor público, uma empresa estadual - a CEMIG - e uma empresa federal - a Eletronorte. Adicionalmente, buscou-se compor um grupo de empresas que representasse, ainda que em pequena escala, o perfil das empresas do setor elétrico brasileiro, bem como as três grandes áreas que configuram o setor elétrico: geração, transmissão e distribuição de energia.

Os dados foram coletados por meio de pesquisa documental e entrevistas. Foram consultados arquivos, registros e documentos das empresas pesquisadas, tais como Relatórios de Atividades, Manuais de Procedimentos, Políticas de Recursos Humanos, entre outros. Foram ainda disponibilizados documentos que permitiram avaliar as estratégias de P\&D adotadas e das estruturas que estavam sendo implantadas para essas áreas. Foi ainda possível obter informações tais como histórico, missão, políticas, filosofia e estrutura organizacional das empresas pesquisadas.

Foram realizadas vinte e duas entrevistas, entre os meses de janeiro e março de 2007, com funcionários que exercem cargos de gestores dos programas de $\mathrm{P} \& \mathrm{D}$ nas empresas pesquisadas, bem como com pessoas-chave que lidam com o gerenciamento desses programas. Foram também entrevistados clientes internos da área de P\&D - os gerentes de projetos, por sua experiência e capacidade de análise crítica dos programas internos desenvolvidos naquela empresa. As entrevistas foram realizadas pelo próprio pesquisador, no ambiente de trabalho dos entrevistados, de acordo com 
o agendamento prévio e a observância do roteiro semiestruturado, elaborado para tal. As entrevistas foram gravadas com a permissão expressa dos entrevistados, cujas identidades foram preservadas.

Para operacionalizar cada uma das cinco dimensões do Modelo Estrela de Galbratih (1995), já descrito na revisão de literatura anteriormente apresentada, foram detalhados os seguintes aspectos no roteiro semiestruturado desenvolvido para nortear o encaminhamento das entrevistas, como se explicita em seguida.

a) Na dimensão Estratégia, foram levantadas questões a respeito do planejamento estratégico de $\mathrm{P} \& \mathrm{D}$, bem como do nível de conhecimento existente nas empresas do setor elétrico sobre as tecnologias estratégicas para seu negócio e como os projetos de $\mathrm{P} \& \mathrm{D}$, destinados à produção dessas tecnologias, são tratados na empresa. Pesquisou-se ainda o grau de alinhamento da estratégia adotada com os recursos disponibilizados para sua implementação.

b) Na dimensão Estrutura, analisaram-se, no contexto da estrutura organizacional da empresa, a localização da área gestora do programa de $\mathrm{P} \& \mathrm{D}$, o nível de relacionamento existente entre o pessoal da área gestora do programa de P\&D, os gerentes de projetos, a ANEEL e a rede de parceiros. Buscouse ainda identificar a existência de conflitos internos, o processo de internalização dos produtos dos projetos e as tendências futuras para essa área.

c) Na dimensão Processos, foram levantados os macroprocessos desenvolvidos nos setores de P\&D, o fluxo de informações utilizado, o nível de informatização dos processos desenvolvidos e o grau de alinhamento entre os processos, a estratégia e a estrutura organizacional adotada.

d) Na dimensão Pessoas, foram identificados o perfil exigido ou desejado para as pessoas que trabalham com a gestão e a execução das atividades de P\&D na empresa, as formas utilizadas para o desenvolvimento e a fixação dessas pessoas na empresa e a percepção de outras áreas acerca das atividades desenvolvidas pelo pessoal de P\&D.

e) Na dimensão Recompensa, foram analisados os mecanismos ou programas de incentivo às atividades de pesquisa, a eficácia desses mecanismos, as formas de divulgação, tanto interna quanto externa, dos programas de $\mathrm{P} \& \mathrm{D}$, as formas de alocação de horas, a avaliação e a remuneração das atividades de pesquisa e o nível de reconhecimento e institucionalização das atividades de pesquisa nas empresas.

A análise das entrevistas foi realizada por meio da técnica de análise de conteúdo, utilizando-se uma estratégia analítica dos casos, especialmente nos aspectos que foram relatados como particularmente importantes nas escolhas do modelo de arquitetura organizacional adotado pelas empresas, na percepção dos entrevistados acerca das experiências que estavam sendo implementadas, nas dificuldades e nas possibilidades experimentadas pelos gestores dos processos e em comentários pertinentes obtidos no desenvolvimento da pesquisa. Além disso, procurou-se identificar as ligações causais entre os fenômenos estudados, seus significados e seu alcance em termos da possibilidade de descrever e analisar cada um dos casos pesquisados.

\section{Os Resultados DA PEsQUISA}

A análise do material coletado nas entrevistas e na análise documental possibilitou a compreensão detalhada do fenômeno estudado em cada uma das empresas pesquisadas, nas cinco dimensões do modelo pesquisado. Para este artigo, optou-se pela utilização do recorte das dimensões do modelo de Galbratih (1995), em que a situação das empresas pesquisadas vai sendo gradativamente analisada. A seguir, estarão sendo relatadas as principais conclusões do estudo. 


\section{Estratégia}

As empresas pesquisadas apresentaram, basicamente, dois tipos de estratégias para a condução dos projetos de P\&D. Num primeiro grupo, estão as empresas, cujas políticas para captação e seleção de projetos de $\mathrm{P} \& \mathrm{D}$ se inserem no contexto das macroestratégias, ou das estratégias empresariais desenvolvidas para a empresa como um todo. Neste grupo, se enquadram prioritariamente a CEMIG e a Eletronorte. Num segundo grupo, formado pela CPFL e a Eletropaulo, identifica-se a existência de planejamentos específicos de $\mathrm{P} \& \mathrm{D}$ elaborados com base no estabelecimento de linhas claras de pesquisa.

O processo de planejamento de $\mathrm{P} \& \mathrm{D}$ da CPFL, diferentemente daquele da Eletropaulo, apresenta duração executiva de cinco anos e abordagem prospectiva de mais cinco anos, o que permite à empresa planejar projetos encadeados em dada linha de pesquisa ou interconectados a várias e até diferentes linhas. Os novos projetos surgem como decorrência dos projetos em andamento ou já concluídos, o que reduz a necessidade de captar projetos inteiramente novos a cada ciclo. Essa metodologia também permite que a empresa priorize projetos que envolvam tecnologias-chave ou emergentes e que, normalmente, demandariam mais tempo para serem concluídos. A situação identificada na CPFL parece encaixar-se bem no conceito de inovação incremental que facilita o desenvolvimento de novas tecnologias.

Essa sistemática também incentiva a realização de arranjos produtivos com empresas privadas de forma mais permanente e em perspectiva de longo prazo. As redes que se formam no entorno da empresa passam a funcionar como rede diversificada de parceiros, devido à confiança que se desenvolve em relação à empresa proponente (no caso, a CPFL), e lhes permite visualizar planejamentos e investimentos de longo prazo. A manutenção de uma rede fixa de parceria também possibilita o estreitamento das relações e introduz certa racionalização da carga de trabalho, dado o acúmulo de conhecimento que vai gradativamente sendo incorporado pelas empresas acerca dos processos, dos procedimentos e das exigências da concessionária e da ANEEL.

Por outro lado, na CPFL quase não existe a captação de propostas de projetos entre seus empregados, o que faz com que a empresa encontre dificuldades para identificar internamente gerentes de projetos, uma vez que a ANEEL exige que os projetos sejam monitorados por funcionários da empresa. Essa dificuldade se dá porque os empregados, muitas vezes, não se identificam com os projetos, não se sentem comprometidos com a ideia e, principalmente, porque não conseguem visualizar, de forma clara, ganhos imediatos para a empresa, além de ter de agregar mais uma atividade à sua rotina de trabalho. Esse aspecto pode ser objeto de melhorias por parte da empresa, por meio de políticas, como, por exemplo, o desenvolvimento da conscientização dos funcionários em relação à relevância dos projetos de $\mathrm{P} \& \mathrm{D}$ e a implementação de incentivos e recompensas financeiras e institucionais aos empregados que se dispuserem a coordenar projetos.

Na Eletropaulo, os projetos são priorizados segundo um planejamento baseado em onze rotas tecnológicas definidas pela empresa, a partir do que a área de P\&D considera como representativas da visão da empresa para o futuro. Na formulação das rotas são definidos os percentuais de aplicação dos recursos de $\mathrm{P} \& \mathrm{D}$, de acordo com o grau de importância que essa rota possa representar para a empresa e, consequentemente, estabelece a importância estratégica de cada uma delas.

Essas rotas foram levantadas via trabalho de prospecção interno e validadas por meio de questionário respondido internamente pelos diretores, vice-presidentes, gerentes das áreas e gerentes de projeto e, externamente, pela ANEEL, pela agência reguladora e fiscalizadora dos serviços de energia do Estado de São Paulo (Comissão de Serviços Públicos de Energia [CSPE]), por parceiros e pesquisadores.

Em síntese, pode-se concluir que a CPFL e a Eletropaulo estão desenvolvendo suas estratégias de P\&D de forma a incentivar maior interação com o ambiente externo, priorizando a formação de parcerias e possibilitando que outros stakeholders auxiliem na elaboração das prioridades estratégicas. O horizonte é de longo prazo, o desenvolvimento de projetos privilegia o desenvolvimento 
incremental e a definição de prioridades é flexível, o que possibilita a incorporação de novas temáticas de pesquisa.

No segundo grupo de empresas, no qual se identificam a CEMIG e a Eletronorte, constata-se a incipiência dos processos específicos de planejamento de P\&D. Essas empresas utilizam-se, como norteador dos processos de captação e seleção de projetos, do planejamento estratégico institucional que fornece diretrizes bastante amplas em termos de seu escopo, porém vagas em relação aos aspectos mais específicos de P\&D. Assim, esse instrumento possibilita grande variedade de interpretações no que se refere às prioridades da empresa para a proposição e o desenvolvimento específico de projetos.

Nessa perspectiva, as empresas geralmente realizam a captação de propostas, tanto interna quanto externamente, sem desdobramento da estratégia empresarial em linhas específicas de pesquisas. Daí resulta o desenvolvimento de projetos pouco encadeados entre si, desvinculados de linhas prioritárias de pesquisa, guiados por motivações mais específicas do que institucionais e aleatórios no que se refere a possíveis ganhos advindos de seu desenvolvimento.

Não se pode afirmar que essa alternativa não vá trazer ganhos efetivos para as empresas que adotam essa estratégica, mesmo porque, no Brasil, são recentes os investimentos das concessionárias em P\&D. Ademais, não constituiu objetivo desta pesquisa avaliar os ganhos resultantes dos projetos financiados. A percepção que se teve, contudo, na realização das entrevistas é de que há grande ênfase dos envolvidos no sentido de ressaltar a importância de que as estratégias e políticas de P\&D estivessem alinhados à sistemática de captação e seleção de projetos.

Conforme observaram Pompermayer e Melo (2005), o grande desafio da ANEEL e também das empresas do setor elétrico é conseguir manter o equilíbrio entre o cumprimento dos objetivos do programa e alguns aspectos até contraditórios que se colocam entre eles, tais como: possibilitar a inovação tecnológica do setor, ao mesmo tempo que se mantém a racionalidade do processo, de forma a assegurar o retorno dos investimentos realizados, mediante ampliação e melhoria na qualidade dos serviços prestados ao consumidor. Para tal, investimentos centrados em clara agenda de pesquisa talvez possa proporcionar maiores benefícios do que a aplicação dos recursos em projetos específicos, que podem apresentar mais ganhos para a empresa em si do que para o setor elétrico como um todo. Além disso, um número mais reduzido de projetos de $\mathrm{P} \& \mathrm{D}$ poderia possibilitar às empresas gerenciar melhor sua carteira, reduzindo as despesas operacionais e facilitando a racionalização dos processos.

\section{Estrutura}

Assim como na dimensão Estratégia, é possível identificar, nas empresas pesquisadas, duas formas de estruturação para gestão dos programas de $P \& D$ das empresas pesquisadas. Um primeiro grupo pode ser formado com as empresas CPFL e Eletropaulo, ambas privadas, que adotaram estratégias associadas à redução de custos internos, buscando estruturas mais informais caracterizadas pela utilização menos intensiva de mão de obra própria para o gerenciamento de seus programas de P\&D. No segundo grupo, estão a CEMIG e a Eletronorte, ambas públicas, que criaram estruturas mais formais, no primeiro ou no segundo escalão da hierarquia organizacional.

As empresas pertencentes ao segundo grupo, CEMIG e Eletronorte, trabalham com estrutura bastante parecida, pois a Eletronorte, de forma claramente expressa nas entrevistas, teve como principal referência a estrutura que estava sendo implementada pela CEMIG. Assim, ambas as empresas trabalham em três níveis do programa - estratégico, tático e operacional - com algumas peculiaridades que são mencionadas aqui.

Em ambas as empresas, foram criados comitês formados por representantes dos órgãos de primeiro escalão na hierarquia organizacional, com poder deliberativo no nível corporativo sobre todos os macroprocessos afetos a P\&D. Esse caráter representativo e formal dos comitês serve para conferir maior visibilidade e credibilidade ao programa ao longo de toda a cadeia hierárquica da empresa. 
Para viabilização do programa no nível tático, também foram gerados setores formalmente estruturados, mas observa-se que, na CEMIG, esse setor não consegue cumprir integralmente seu papel, uma vez que atua quase exclusivamente na rotina operacional do programa. Isto ocorre, provavelmente, em virtude da inexistência de pessoal para atuar no nível operacional, o que força o nível tático a atuar nessa dimensão e ocupa, praticamente, todo seu tempo de trabalho.

Ao contrário do que ocorre na CEMIG, na qual praticamente ainda não existe uma estrutura específica para atuação no nível operacional, na Eletronorte esse nível é exercido por coordenadores locais de P\&D - representantes da área gestora do programa de P\&D da ANEEL. Esses coordenadores interagem como rede de relacionamento com os gerentes de projeto e com as instituições de ensino e pesquisa, possibilitando a descentralização do processo e sua disseminação em praticamente todas as unidades da empresa.

No segundo grupo identificado por esta pesquisa, aquele formado pela CPFL e pela Eletropaulo, foram criadas estruturas informais de coordenação de $\mathrm{P} \& \mathrm{D}$, subordinadas a um órgão de terceiro escalão na hierarquia organizacional, porém com autonomia sobre todos os demais níveis hierárquicos, incluindo os superiores, no que se refere às questões de P\&D.

A política dessas empresas, de utilização do mínimo necessário de mão de obra própria para a condução do programa de P\&D, já havia sido observada, há algum tempo, por Visacro (2005), que assim descreveu o problema.

Têm sido constituídos setores para gestão de tecnologia na maior parte das grandes concessionárias, que objetivam assegurar eficiência na realização dos investimentos em pesquisa na busca de um melhor retorno para os mesmos. Entretanto, uma parcela significativa das empresas não configurou quadros adequados para o gerenciamento de seus programas (Visacro, 2005, p. 4).

A falta de estrutura adequada para dar sustentação ao programa de P\&D da ANEEL fez com que as empresas que adotaram essa política buscassem soluções diversificadas. A CPFL criou a seu redor uma sólida rede de parceiros, denominados como WEBTec, composta por núcleos operacionais que englobam empresas de tecnologia, universidades, centros de pesquisas, fabricantes e outros, em que ela deposita a carga de trabalho operacional. Para atuação, porém, nos demais níveis, principalmente no estratégico, observa-se grande centralização em relação a poucos setores e dependência de pequeno número de pessoas. Esse aspecto vem sendo contornado na CPFL por meio da adoção de uma política de sucessão e do desenvolvimento de um processo que facilite a transferência dos conhecimentos gerados pelos parceiros.

Já a alternativa implementada pela Eletropaulo, que dispõe de um quadro de empregados ainda mais reduzido para a gestão de $\mathrm{P} \& \mathrm{D}$, foi a distribuição desse trabalho por toda a empresa, utilizando-se da capacidade e da expertise que os gerentes de projetos já desenvolveram para trabalharem com o sistema matricial.

Os demais aspectos analisados dentro da dimensão Estrutura, tais como conflitos existentes devido à presença de uma estrutura informal matricial, conflitos de relacionamento com a ANEEL e com a rede de parceiros e problemas de internalização dos resultados de P\&D aparecem em todas as empresas pesquisadas, com maior ou menor intensidade, como será discutido a seguir.

Nessas empresas, observa-se crescente utilização de parcerias para o desenvolvimento de projetos de $\mathrm{P} \& \mathrm{D}$. Essa tendência se deve, principalmente, a dois motivos: os projetos de $\mathrm{P} \& \mathrm{D}$ tendem a requerer, cada vez mais, mão de obra capacitada e com expertise para a condução da pesquisa, o que não está facilmente disponível nas empresas do setor elétrico; a condução do projeto requer muita dedicação de tempo, o que não é disponibilizado aos empregados próprios.

A pesquisa realizada por Pompermayer e Melo (2005) já apontava, no contexto dos cinco ciclos analisados (1998/1999, 1999/2000, 2000/2001, 2001/2002 e 2002/2003), uma evolução expressiva no número de empresas parceiras participantes do programa P\&D. De maneira geral, todos os parceiros avaliavam a relação entre a empresa financiadora e a rede estabelecida como um processo de 
aprendizado, em que os agentes envolvidos têm evoluído e aprimorado suas práticas e processos, especialmente por causa da necessidade de responder de forma eficiente às demandas dos investidores e contratantes (Brittes \& Melo, 2005). Esse elevado nível de exigência tem imposto certo processo de seleção natural; assim sobrevivem apenas os parceiros que demonstram expressiva capacidade de executar as pesquisas contratadas e desaparecem aqueles que não demonstram capacidade de desenvolvimento compatível com o programa (Visacro, 2005).

Um aspecto interessante a se observar é que, exceto a CPFL, todas as outras empresas valorizam a proteção da propriedade intelectual resultante dos projetos de $P \& D$, o que tem causado também lentidão no processo de tramitação dos projetos de pesquisa, emperrando a contratação dos projetos e retardando o início das pesquisas. Os atrasos decorrentes dos trâmites jurídicos internos, aliados à demora na aprovação dos projetos pela ANEEL, acabam por desestimular os gerentes dos projetos e, em alguns casos, desestruturar grupos executores da pesquisa. Assim, análises mais detalhadas do custo-benefício decorrentes dessas contendas jurídicas deveriam ser feitas para avaliar se, realmente, as receitas obtidas nos ciclos passados compensam os prejuízos gerados.

\section{Processos}

Em virtude das regras impostas pela ANEEL, não se percebem diferenças substanciais entre os macroprocessos desenvolvidos pelas empresas do setor elétrico pesquisadas. Esses, com algumas pequenas diferenças, estão basicamente relacionados ao levantamento de necessidades, captação de propostas, avaliação, seleção e priorização de projetos, aprovação na ANEEL, acompanhamento da execução e avaliação dos resultados. Apenas a CPFL, em virtude de seu planejamento estratégico de P\&D, não executa o levantamento de necessidades e a captação de propostas.

Outra dificuldade enfrentada por esta pesquisa para comparar os processos organizacionais entre as empresas analisadas foi a constatação da existência de estruturas organizacionais muito diversificadas para gerir os programas de $P \& D$. Assim, em consequência da estratégia e da estrutura adotadas pela empresa, diferentes procedimentos internos são adotados para a realização de cada macroprocesso.

A questão mais relevante a destacar aqui se refere ao nível de informatização utilizado pelas concessionárias para dar suporte às equipes de $\mathrm{P} \& \mathrm{D}$ independentemente do processo utilizado. Embora nenhuma das empresas pesquisadas tenha desenvolvido ainda sistemas integrados de gestão de projetos e se encontre até mesmo em estágios de desenvolvimento muito diferenciados, todas reconhecem a importância da existência de tais sistemas. Das empresas pesquisadas, a Eletronorte é a que parece estar em estágio mais avançado nesse aspecto. Seus sistemas encontram-se em fase avançada de desenvolvimento e já estão parcialmente integrados, cobrindo desde a fase de levantamento das necessidades de P\&D da empresa até a aprovação final do projeto na ANEEL. Não estão desenvolvidas ainda as etapas de seleção e priorização de projetos, bem como de acompanhamento da execução e de avaliação dos resultados. A questão do gerenciamento dos processos representa, na verdade, um dos aspectos mais incipientes nas concessionárias pesquisadas.

Outro ponto percebido é que a maioria das empresas pesquisadas prefere desenvolver todos os processos internamente, em alguns casos, utilizando-se do apoio de outras áreas da empresa, como, por exemplo, da área de suprimento e da jurídica. Essa alternativa foi apontada como um dos principais entraves, porque, como essas áreas têm que atender à empresa como um todo, isso acaba acarretando demora na análise dos contratos de convênio, com consequente atraso na execução do projeto. Já se encontra em análise, em algumas concessionárias, a estruturação de um setor jurídico exclusivo para análise de contratos e assuntos relacionados a $\mathrm{P} \& \mathrm{D}$, a fim de agilizar o processo de contratação; em nenhuma delas, porém, tal alternativa encontra-se implementada.

\section{Pessoas}

A análise da dimensão Pessoas mostra que, nas empresas privadas, em que não existem empecilhos legais para contratação, a escassez de pessoal decorre da política estabelecida de utilizar um quadro 
mínimo de empregados próprios na gestão dos programas de P\&D. As empresas públicas, por sua vez, embora expressem o interesse e a importância de disporem de empregados com perfil adequado, não chegam a fazê-lo em virtude das regras impostas pela legislação que regulamenta a contratação de servidores públicos, de autarquias e de empresas públicas. Assim, como não conseguem contratar o empregado com o perfil desejado, resta-lhes investir no desenvolvimento de seu quadro próprio.

A CEMIG, por exemplo, mesmo antes da promulgação da Lei n. 9.991/2000, já investia no treinamento do pessoal envolvido com a gestão de P\&D. Em 1999, por meio de um convênio com a FIA/FEA/USP, implementou a metodologia de Gestão Estratégica de Tecnologia com o objetivo de alinhar a tecnologia aos objetivos estratégicos da empresa. Também o projeto Desenvolvimento de um Sistema Integrado de Gestão Estratégica da Tecnologia e Inovação foi desenvolvido com o objetivo de criar um sistema integrado e capacitar, em programas de MBAs e/ou mestrados, as pessoas ligadas à gestão de $\mathrm{P} \& D$. Nessa mesma linha, encontra-se a Eletronorte, que implementou um projeto de treinamento cujo objetivo é capacitar o pessoal que gerencia os programas de $\mathrm{P} \& \mathrm{D}$, bem como os coordenadores locais em questões tais como gestão de tecnologia e acompanhamento de projetos.

No caso dos gerentes de projeto, esses geralmente conseguem desenvolver-se por meio da inserção em programas formais de treinamento e capacitação, tais como cursos de pós-graduação em áreas de suporte para que os auxiliem no desenvolvimento de seus projetos de pesquisa. Como bem observou Visacro (2005), essa, porém, é uma decisão de natureza pessoal do gerente de projeto, que deveria ser institucionalizada pelas empresas, uma vez que, por meio dos recursos de $\mathrm{P} \& \mathrm{D}$, as empresas poderiam capacitar e desenvolver seu quadro de empregados sem incorrer em excessivos custos adicionais.

As empresas privadas, por sua vez, como conseguem contratar pessoas com o perfil desejado, não necessitam investir tanto em treinamento. Outra razão apontada por essas empresas para justificar seus escassos investimentos em treinamento é o comprometimento causado nas rotinas de trabalho, quando ocorre o deslocamento do funcionário para esses programas, alegação que parece bastante tênue em virtude dos benefícios que essa prática pode trazer para a empresa. Assim, um dos maiores problemas observados nessas empresas é que o processo de transferência e retenção do conhecimento acaba inevitavelmente sendo feito pela rede de parceiros e, muitas vezes, não é utilizado em benefício da empresa que financiou esse desenvolvimento, já que seus empregados não se encontram preparados para absorvê-los. Conforme observado anteriormente, o incentivo e a institucionalização de programas de desenvolvimento de pessoal próprio podem tornar-se um dos maiores ganhos que o programa de $\mathrm{P} \& D$ poderia trazer para as empresas financiadoras.

\section{Recompensas}

Basicamente, pode-se afirmar que nenhuma das empresas pesquisadas dispõe de sistemas específicos para remunerar os empregados que lidam com a área de P\&D. A única concessionária que está atualmente desenvolvendo sistemas com esse objetivo específico é a Eletronorte, que se encontra em processo de estruturação e teste de dois mecanismos de recompensa: o primeiro estabelece uma premiação financeira para aqueles gerentes que se destacarem e produzirem mais na condução dos projetos de P\&D; o segundo considera o pagamento aos gerentes de projetos, de até $20 \%$ sobre os direitos industriais das patentes originadas por projetos de pesquisa, pagos pelo prazo que durar a patente.

Apesar de as posições manifestadas durante as entrevistas serem dúbias quanto à eficácia da utilização de recompensas externas, principalmente pecuniárias, para a premiação de desempenhos superiores, a Eletronorte está considerando a possibilidade de premiar o pessoal envolvido no desenvolvimento de projetos. Essa alternativa é vista como uma forma de aumentar o número de participantes, bem como um modo de despertar interesse e melhorar o desempenho de seu pessoal. As outras empresas pesquisadas mencionam, de forma vaga, a existência de motivações intrínsecas para justificar a participação dos empregados em programas de $\mathrm{P} \& \mathrm{D}$, mas há que levantar a possibilidade de que essa alegação seja mais uma forma de justificar a inexistência de tais programas do que propriamente de atribuir validade a elas. 
Algumas das empresas pesquisadas buscam divulgar resultados obtidos por meio dos projetos desenvolvidos pelos empregados em revistas de circulação externa, alternativa vista como forma de motivar o pessoal, como incentivo ao desenvolvimento profissional de seus gerentes de projetos, bem como para ampliar o grau de percepção de toda a empresa para a importância da área de P\&D.

Apesar das dificuldades de implantação inerentes a todos os processos e considerando-se que são recentes as atividades de $P \& D$ no setor elétrico brasileiro, é unânime a percepção nas empresas pesquisadas de que o programa de P\&D da ANEEL já está internalizado. Essa internalização, contudo, aparece ainda bastante frágil, porquanto, indagados sobre o que poderia ocorrer, caso a lei seja revogada, os entrevistados afirmaram que os níveis de investimento não se manteriam em virtude da inexistência de uma metodologia de avaliação dos impactos dos projetos de P\&D, tanto sob o aspecto econômico, na forma de geração de conhecimento e de bens intangíveis, quanto no aspecto socioambiental.

Assim, acredita-se que a adoção de uma forma de remuneração variável, em que o gerenciamento de projetos seja atividade reconhecida em sua composição, e a adoção de metodologia de avaliação socioeconômica do retorno do investimento dos projetos de P\&D fortalecerão enormemente o programa, motivando os empregados a se engajarem mais na condução dos projetos e subsidiando a análise e seleção de projetos de $\mathrm{P} \& \mathrm{D}$ que possam trazer retornos para as concessionárias e justificar os investimentos realizados.

\section{CONSIDERAÇÕES FINAIS}

Embora a pesquisa realizada constitua um passo inicial na compreensão dos processos de internalização das atividades de P\&D nas empresas brasileiras do setor elétrico, algumas conclusões podem ser delineadas a partir desse estudo, e mesmo de forma comparada com alguns outros estudos já realizados por pesquisadores brasileiros. Inicialmente foi utilizada a pesquisa realizada por Maisonnave e Rocha-Pinto (2008), para identificar as percepções dos entrevistados em relação às 19 dimensões que haviam sido anteriormente propostas pelos autores. Como ressaltaram os autores, esse mapeamento é interessante no sentido de auxiliar a identificação do posicionamento das empresas pesquisadas em relação às diversas dimensões pesquisadas, mas não permite análise mais conclusiva. A Tabela 1 sintetiza as principais posições expressas nas entrevistas realizadas:

Tabela 1

\section{Os Impactos das Ações de P\&D nas Empresas Pesquisadas}

\begin{tabular}{|c|c|c|c|c|}
\hline & \\
\hline & CPFL & Eletropaulo & Cemig & Eletronorte \\
\hline $\begin{array}{l}\text { A inovação é vista como atividade estratégica } \\
\text { dentro da empresa }\end{array}$ & Sim & Sim & Sim & Sim \\
\hline $\begin{array}{l}\text { Os funcionários da empresa agregam } \\
\text { propostas de melhoria e sugestões de temas }\end{array}$ & Sim & Sim & Sim & Sim \\
\hline $\begin{array}{l}\text { As ações relacionadas a inovação e P\&D } \\
\text { enfrentam resistências internas? }\end{array}$ & Não & Não & Não & Não \\
\hline $\begin{array}{l}\text { Os clientes internos reconhecem o esforço de } \\
\text { P\&D da empresa. }\end{array}$ & Sim & Sim & Sim & Sim \\
\hline $\begin{array}{l}\text { A burocracia da empresa afeta o processo de } \\
\text { gestão de inovação e P\&D. }\end{array}$ & Sim & Sim & Sim & Sim \\
\hline $\begin{array}{l}\text { Os avanços tecnológicos influenciam as } \\
\text { decisões de investimento em P\&D e inovação. }\end{array}$ & Sim & Sim & Sim & Sim \\
\hline
\end{tabular}




\section{Tabela 1 (continuação)}

\begin{tabular}{lcccc}
\cline { 2 - 5 } & CPFL & Eletropaulo & Cemig & Eletronorte \\
\cline { 2 - 5 } $\begin{array}{l}\text { As instituições de pesquisa cumprem o seu } \\
\text { papel de parceria de maneira satisfatória. }\end{array}$ & $\begin{array}{c}\text { Em grande } \\
\text { parte }\end{array}$ & $\begin{array}{c}\text { Em grande } \\
\text { parte }\end{array}$ & $\begin{array}{c}\text { Em grande } \\
\text { parte }\end{array}$ & $\begin{array}{c}\text { Em grande } \\
\text { parte }\end{array}$ \\
$\begin{array}{l}\text { As associações, das quais a empresa participa, } \\
\text { auxiliam o processo de P\&D. }\end{array}$ & Sim & Sim & Sim & Sim \\
$\begin{array}{l}\text { Os clientes externos reconhecem o esforço de } \\
\text { P\&D da empresa. }\end{array}$ & Sim & Sim & Sim & Sim \\
$\begin{array}{l}\text { As inovações advindas de P\&D são levadas ao } \\
\text { mercado. }\end{array}$ & Sim & Sim & Sim & Informado \\
$\begin{array}{l}\text { Os resultados de P\&D estão, em sua maioria, } \\
\text { relacionados à melhoria contínua. }\end{array}$ & Sim & Sim & Sim & Sim \\
$\begin{array}{l}\text { Os resultados de P\&D podem mudar } \\
\text { significativamente o negócio da empresa. }\end{array}$ & Não & Não & Não & Não \\
$\begin{array}{l}\text { Os investimentos em P\&D trazem retorno } \\
\text { financeiro à empresa. }\end{array}$ & Não & Não & Não & Não \\
$\begin{array}{l}\text { Os objetivos da regulação do setor elétrico } \\
\text { relacionados a P\&D foram alcançados. }\end{array}$ & Sim & Sim & Sim & Sim \\
$\begin{array}{l}\text { O agente regulador atua de maneira eficiente } \\
\text { na área de Pesquisa e Desenvolvimento. }\end{array}$ & Sim & Sim & Sim & Sim \\
$\begin{array}{l}\text { A fiscalização pelo órgão regulador na área de } \\
\text { P\&D é eficiente. }\end{array}$ & Sim & Sim & Sim & Sim \\
$\begin{array}{l}\text { A fiscalização pelo órgão regulador na área de } \\
\text { P\&D é eficaz. }\end{array}$ & Sim & Sim & Sim & Sim \\
\hline
\end{tabular}

Nota. Fonte: Adaptado de Maisonnave, P. R., \& Rocha-Pinto, S. R. (2008, setembro). Uma análise fenomenológica a respeito da percepção da inovação nos investimentos de pesquisa e desenvolvimento do setor elétrico brasileiro (p. 10). Anais do Encontro Nacional da Associação Nacional de Pós-Graduação e Pesquisa em Administração, Rio de Janeiro, RJ, Brasil, 32.

Adicionalmente, outros resultados podem ser delineados, embora com a ressalva de que as empresas pesquisadas não refletem todas as possibilidades do que pode estar ocorrendo no setor, a despeito de poderem ilustrá-lo de forma bastante ampla. Observou-se, em todas as empresas pesquisadas, dificuldades e problemas relacionados à internalização e à replicação dos produtos e processos resultantes dos projetos de P\&D. Isso pode caracterizar um descompasso entre as pesquisas realizadas e as reais necessidades da empresa ou, ainda, uma falha no processo de previsão de tempo e de recursos que viabilizem a transferência, entre os demais empregados da empresa, do conhecimento adquirido.

Os investimentos nos processos de informatização da etapa de levantamento de necessidades, seleção, priorização e acompanhamento dos projetos de P\&D, embora sejam primordiais para a condução dos programas de $\mathrm{P} \& \mathrm{D}$, ainda não foram amplamente realizados pelas empresas pesquisadas. A maioria delas, entretanto, já diagnosticou o problema, mas ainda não conseguiu desenvolver e implementar plenamente os processos necessários. Isso se deve à complexidade de cada uma dessas etapas e ao tempo requerido para propor, desenvolver, testar e implementar os diversos sistemas necessários. Esse gargalo constitui, certamente, um dos maiores desafios enfrentados pelas empresas.

As formas de motivação de pessoal adotadas pelas empresas pesquisadas, sejam elas implícitas (por meio de recompensas pecuniárias) ou explícitas (por meio de incentivos à capacitação ou divulgação de resultados), têm tido papel muito importante na criação de uma cultura de $P \& D$ e parecem influenciar fortemente a decisão de envolvimento e engajamento dos empregados, especialmente dos 
gerentes de projetos. Observa-se, contudo, que esse ponto merece ainda esforço por parte das empresas pesquisadas, uma vez que, somente em uma delas, se pode notar um movimento ainda incipiente de premiação pecuniária e, em nenhuma delas, se viu uma estratégia de motivação explícita e institucionalizada. Constata-se apenas a existência de movimentos isolados, em geral desvinculados das políticas de Recursos Humanos das empresas.

Quanto ao perfil requerido para o profissional que trabalha no gerenciamento do programa de $\mathrm{P} \& \mathrm{D}$, constatou-se que é aquele de um indivíduo com formação técnica, porém com conhecimento e experiência na área de gestão. As dificuldades de se encontrar esse profissional no mercado, em face das regras de contratação, fazem com que as empresas do setor elétrico sofram as consequências da escassez desse tipo de mão de obra. Ainda que, de forma incipiente, em algumas empresas encontramse desenvolvidos projetos de capacitação desses profissionais. Não se nota, contudo, que tais capacitações sejam fruto de um programa dinâmico de desenvolvimento e, sim, de atitudes mais individuais.

O estímulo à capacitação das pessoas envolvidas no gerenciamento dos projetos de $\mathrm{P} \& \mathrm{D}$, principalmente para os gerentes de projetos, constitui uma das formas mais eficientes de estimular e obter a adesão dos empregados a esses programas. Deve-se, no entanto, ressaltar que essa capacitação deve ser feita de forma institucional, procurando desenvolver o empregado em qualificações requeridas pela empresa e, não, por meio de desenvolvimentos isolados, que, sem dúvida, representam ganhos individuais para o empregado, mas não necessariamente para o programa de desenvolvimento empresarial.

No que se refere à proposta teórica apresentada por Galbratih, o Modelo Estrela (1995) aparece com todas as cinco pontas simétricas, sugerindo que todas apresentam igual importância na configuração da arquitetura organizacional. Nesta pesquisa, contudo, verificou-se que há diferenças na participação de cada uma dessas dimensões na arquitetura organizacional das empresas pesquisadas. Para as empresas do grupo formado pela CPFL e pela Eletropaulo, a Estratégia aparece como a dimensão mais desenvolvida na configuração estrutural da área de P\&D. Já nas empresas do grupo formado pela CEMIG e pela Eletronorte, as dimensões Estrutura, Pessoas e Recompensas aparecem como as dimensões mais desenvolvidas. Em ambos os grupos, devido ao isomorfismo introduzido pela ANEEL quanto às exigências a serem cumpridas, a dimensão Processos aparece com igual relevância.

Em síntese, pode-se perceber que as empresas do setor elétrico ainda estão em fase de estudos, implementação e avaliação das arquiteturas organizacionais mais adequadas ao desenvolvimento de suas atividades de P\&D. As experiências atualmente em desenvolvimento podem servir para introduzir mudanças estruturais na forma como as empresas do SEB as estão incorporando a seu contexto estratégico e organizacional, trazendo a necessidade de que novas pesquisas acompanhem o que vem ocorrendo no setor. Espera-se, assim, que o presente trabalho possa contribuir para pesquisas futuras e, principalmente, que as conclusões aqui enunciadas possam ser úteis às empresas do setor elétrico em seu esforço de transformar a obrigatoriedade do investimento em pesquisas em oportunidades de aprendizado, crescimento e fortalecimento do setor elétrico brasileiro, tão essencial para o crescimento do País como um todo e para a qualidade de vida de seus cidadãos.

Artigo recebido em 25.02.2008. Aprovado em 22.04.2010.

\section{REFERÊNCIAS BIBLIOGRÁFICAS}

Agência Nacional de Energia Elétrica. (2001). Manual dos programas de pesquisa e desenvolvimento tecnológico do Setor Elétrico Brasileiro. Brasília: Autor. 
Aggência Nacional de Energia Elétrica. (2008). Manual do programa de pesquisa e desenvolvimento Utecnológico do setor de energia elétrica. Recuperado em 5 outubro, 2009, de http://www.aneel.gov.br/cedoc/aren2008316_2.pdf

Brittes, J. L. P., \& Melo, A. C., Jr. (2005, outubro). P\&D do setor elétrico - Análise de resultados 21999-2003. Anais do Seminário Nacional de Produção e Transmissão de Energia Elétrica. Euritiba, PR, Brasil, 18.

Burng, T., \& Stalker, G. M. (1961). Mechanistic and organic system. In J. M. Schafritz \& J. S. Ott. (Orgs.), Classics of organizational theory (pp. 209-214). Orlando: Harcourt Brace.

Decreto $n^{\circ}$ 2357, de 27 de outubro de 1997. (1997). Dispõe sobre a destinação ao Programa de Administração Patrimonial Imobiliário da União - PROAP. Brasília, DF. Recuperado em 21 outubro, 2009, de http://www.jusbrasil.com.br/legislacao/111899/decreto-2357-97

Dehgcker, A. F. M. (1998). Métodos e técnicas de pesquisa em turismo. São Paulo: Futura.

Dimaggio, P. J., \& Powell, W. W. (2005). A gaiola de ferro revisitada: isomorfismo institucional e racionalidade coletiva nos campos organizacionais. Revista de Administração de Empresas, 45(2), 74-89.

Dowaldson, L. (1998). Teoria da contingência estrutural. In S. R. Clegg, C. Hardy, \& W. R. Nord (Orgs.), Handbook de estudos organizacionais: modelos de análise e novas questões em estudos organizacionais (Vol. 1, pp. 61-104). São Paulo: Atlas.

Gabjaith, J. R. (1995). Designing organizations - an executive briefing on strategy, structure and process. San Francisco, CA: Jossey Bass.

Gêtsteim, M. S. (1993). Das burocracias mecânicas às organizações em rede: uma viagem \arquitetônica. In D. A. Nadler, M. S. Gerstein, \& R. B. Shaw (Orgs.), Arquitetura organizacional: a chave para a mudança empresarial (pp. 11-38). Rio de Janeiro: Campus.

Gil, A. C. (1991). Como elaborar projetos de pesquisa. São Paulo: Atlas.

Jannuzzi, G. M., \& Gomes, R. D. M. (2002, novembro). A experiência brasileira pós-privatização em programas de eficiência energética e $P \& D$ : lições das iniciativas de regulação e da crise enrergética. Anais do Congresso Brasileiro de Energia, Rio de Janeiro, RJ, Brasil, 9.

Lakatôs, E. M., \& Marconi, M. A. (2001). Fundamentos de metodologia científica (3a ed.). São Paulo: Atlas.

Lawrençe P., \& Lorsch, J. (1973). A empresa e o ambiente: diferenciação e integração administrativa. Pфtrópolis: Vozes.

Lei 9p91, de 24 de julho de 2000. (2000). Dispõe sobre realização de investimentos em pesquisa e desenvolvimento e em eficiência energética por parte das empresas concessionárias, permissionárias e autorizadas do setor de energia elétrica. Brasília, DF. Recuperado em 20 outubro, 2009, de http://www.aneel.gov.br/cedoc/blei20009991.pdf

Maisonnave, P. R., \& Rocha-Pinto, S. R. (2008, setembro). Uma análise fenomenológica a respeito da percepção da inovação nos investimentos de pesquisa e desenvolvimento do setor elétrico brasileiro. Anais do Encontro Nacional da Associação Nacional de Pós-Graduação e Pesquisa em Administração, Rio de Janeiro, RJ, Brasil, 32.

Martini, J. C., \& Maffei, O. M. (2005, outubro). A efetividade dos ciclos de pesquisa e đassenvolvimento em empresas de energia elétrica. Anais do Seminário Nacional de Produção e Transmissão de Energia Elétrica, Curitiba, PR, Brasil, 18. 
Minz̧erg, H., (1995). Criando organizações eficazes - Estruturas em cinco configurações. São Baulo: Atlas.

NadIeff D. A. (1993). Arquitetura organizacional: metáfora para mudança. In D. A. Nadler, M. S. -Gerstein, \& R. B. Shaw (Orgs.), Arquitetura organizacional: a chave para a mudança empresarial (pp. 1-8). Rio de Janeiro: Campus.

Nadler, B. A., Gerstein, M. S., \& Shaw, R. B. (1993). Arquitetura organizacional: a chave para a muddnça empresarial. Rio de Janeiro: Campus.

Nadlen, D. A., \& Shaw, R. B. (1993). Arquiteturas organizacionais para o século XXI. In D. A. Nadler, M. S. Gerstein, \& R. B. Shaw (Orgs.), Arquitetura organizacional: a chave para a mudança empresarial (pp. 263 - 273). Rio de Janeiro: Campus.

Nadler,_D. A., \& Tushaman, M. L. (1993). Projetos de organizações com boa adequação: uma moldura para compreender as novas arquiteturas. In D. A. Nadler, M. S. Gerstein, \& R. B. Shaw (Orgs.), Arquitetura organizacional: a chave para a mudança empresarial (pp. 39-56). Rio de Janeiro: Campus.

Pompermayer, M. L., \& Melo, A. C., Jr. (2005, outubro). Perfil dos projetos de pesquisa e desenvolvimento tecnológico no setor elétrico brasileiro. Anais do Seminário Nacional de Produção e Transmissão de Energia Elétrica, Curitiba, PR, Brasil, 18.

Resolução ANEEL n. 242, de 24 de julho de 1998. (1998). Dispões sobre a resolução de aplicação de $1 \%$ da receita operacional anual dos concessionários de serviço de distribuição de energia elétrica para o desenvolvimento de ações de incremento à eficiência no uso e oferta de energia elétrica. Brasília, DF. Recuperado em 20 outubro, 2009, de http://www.aneel.gov.br/cedoc/res1998242.pdf

Resplução ANEEL n. 261, de 03 de setembro de 1999. (1999). Dispões sobre a regulamentação da pbrigatoriedade de aplicação de recursos das Concessionárias de energia elétrica em ações de ¿ombate ao desperdício de energia elétrica e pesquisa e desenvolvimento tecnológico do setor elétrico para o biênio 1999/2000. Brasília, DF. Recuperado em 20 outubro, 2009, de http://www.aneel.gov.br/cedoc/RES1999261.PDF

Resolıção ANEEL n. 271, de 17 de julho de 2001. (2001). Dispões sobre a autorização, para fins de rregularização, da Companhia Energética Santa Elisa para estabelecer-se como Produtor Independente de Energia Elétrica. Brasília, DF. Recuperado em 20 outubro, 2009, de http://www.aneel.gov.br/cedoc/res2001271.pdf

Salgado, L. H., \& Motta, R. S. (2005). Marcos regulatórios no Brasil: o que foi feito e o que falta fazer. Rio de Janeiro: IPEA.

SilvąE. L., \& Menezes, E. M. (2001). Metodologia da pesquisa e elaboração de dissertação (3a ed.). Florianópolis: Laboratório de Ensino a Distância da UFSC.

Silvă,F. L. S., Mora, C. H., Jr., \& Stal, E. (2008, agosto). Contribuições de um sistema CRM às inovações de processos em uma empresa distribuidora de energia elétrica. Anais do Simpósio de Administração da Produção, Logística e Operações Internacionais, São Paulo, SP, Brasil, 11.

Visącro, $S$ (2005, outubro). Programa de P\&D da ANEEL: concepção, falácias e novos desafios. Anais do Seminário Nacional de Produção e Transmissão de Energia Elétrica, Curitiba, PR, Brasil, 18.

Woodward, J. (1977). Organização industrial: teoria e prática. São Paulo: Atlas.

Yin, R. 长 (2001). Estudo de caso: planejamento e método. Porto Alegre: Bookman. 